\title{
Trayectoria escolar y de vida de Angelo Cabrera y su lucha por el derecho a la educación
} Angelo Cabrera's School and Life Trajectories, and His Struggle for the Right to Education

\author{
María Mercedes Ruiz Muñoz \\ Universidad Iberoamericana Ciudad de México, México \\ mercedes.ruiz@ibero.mx
}

\begin{abstract}
RESUMEN
En este trabajo se presentan los resultados de una investigación en marcha acerca de la trayectoria escolar y de vida en contextos migratorios, así como de la lucha por el derecho a la educación. Se parte de la voz del protagonista, resultado de entrevistas a profundidad y diálogos informales para construir, de manera conjunta, las tramas y las unidades discursivas (meta-categorías y categorías) propias de los estudios de corte cualitativo. El escrito da cuenta del camino recorrido por nuestro protagonista, de la vida diaria de un migrante y de lo que hizo posible su derecho a la educación. Angelo Cabrera, además de trabajar para apoyar a sus padres, descubrió que la educación es un derecho humano y exigió su acceso y permanencia a la educación superior. Durante su trayectoria escolar aconteció el atentado terrorista a las Torres Gemelas en la Ciudad de Nueva York, el 11 de septiembre del 2001, lo cual generó una política anti migratoria y que las universidades aplicaran el pago de colegiatura "fuera del estado"a los estudiantes migrantes. Los estudiantes se vieron desolados y muchos de ellos abandonaron la universidad. Ante este suceso, un grupo de jóvenes inmigrantes mexicanos decidió salir de la sombra, como bien lo señala Angelo, para dar la cara para luchar por el derecho a la educación superior. Este trabajo permite dar cuenta de la configuración del sujeto de derecho a partir de la exigibilidad en la lucha social y la justiciabilidad en el terreno jurídico.
\end{abstract}

Palabras clave: trayectoria escolar, derecho a la educación, migración, exigibilidad

\section{ABSTRACT}

This paper presents the results of an ongoing research about school and life trajectories in migratory contexts, as well as the struggle for the right to education. By the protagonist's voice -result of in-depth interviews and informal dialogues - we built, together, the frames and discursive units (meta-categories and categories) characteristic of qualitative studies. The document gives an account of the path traveled by our protagonist, of the daily life of a migrant and of that which made possible his right to education. Angelo Cabrera, in addition to working to support his parents, learned that education is a human right and demanded his access and permanence to higher education. During his school trajectory, the terrorist attack on the Twin Towers in New York City took place on September 11, 2001, which generated an anti-immigration policy and the universities applied the payment of an out-of-state tuition to migrant students. That was heartbreaking for the students and many of them dropped out of college. In response to this event, a group of young Mexican immigrants decided to leave the shadows, as Angelo points out, to face and to fight for their right to higher education. This work allows to give an account about the configuration of the subject of law from the enforceability in the social struggle and the justiciability in the legal field.

Keywords: school trajectory, right to education, migration, enforceability 
Un estudiante extranjero tiene Visa, tiene derechos.

Un estudiante indocumentado no tiene derechos...

Angelo Cabrera

\section{INTRODUCCIÓN}

Este trabajo se inscribe en una línea de investigación de larga data, referida al "Derecho a la educación, la justicia escolar y la política educativa”. Se parte de la voz de los protagonistas para construir, de manera colaborativa, narrativas biográficas de las trayectorias escolares y de vida en contextos vulnerables, con el propósito de dar cuenta de las condiciones que hacen posible el acceso, la permanencia y el logro educativo de los estudiantes. Con contextos vulnerables se alude a las condiciones de precariedad y desventaja de los jóvenes que migran a los Estados Unidos en los ámbitos laboral, social y educativo. De acuerdo con Martínez (2000, p. 7), "se observa un contexto de vulnerabilidad en la migración que se establece entre países limítrofes, traducida en condiciones desventajosas en el plano de logros educativos e inserción laboral, y en un probablemente rápido tránsito hacia la vida adulta”.

Para fines de este artículo, se presenta la trayectoria de vida y escolar de un migrante mexicano que arribó a la Ciudad de Nueva York en los ańos noventa para trabajar y ayudar a sus padres, mientras que, en su vida diaria, construyó su camino para continuar con sus estudios, ingresar a la universidad y luchar por el derecho a la educación superior. A lo largo de la narrativa de vida de Angelo Cabrera, se muestra cómo se fue empoderando como sujeto de derecho y las acciones emprendidas en su lucha, a pesar de los temores y los miedos que se gestaron en él como migrante. Angelo Cabrera decidió salir de la sombra y dar la cara para la defensa del derecho a la educación a través de diversas manifestaciones político-pedagógicas como una huelga de hambre, denuncias ante los medios periodísticos, articulación con redes de líderes comunitarios y académicos universitarios, cabildeo con los tomadores de decisiones y presión política para modificar la legislación.

Ante esta situación, cabe preguntarse, ¿qué trayecto de vida va construyendo para configurarse como sujeto de derecho?, ¿cómo vive el acceso y la permanencia en la universidad en su condición 
de inmigrante ilegal?, ¿qué sentidos otorga a su lucha por el derecho a la educación? Para dar respuesta a estas preguntas se parte del paradigma cualitativo, porque permite adentrarnos a la vida de las personas a través de entrevistas a profundidad, relatos orales y escritos del protagonista, así como entrevistas a otros informantes clave. Además, se problematiza la discusión por medio de la teoría del reconocimiento (Honneth, 2010) y su relación con la justicia y la exclusión social, en particular de los grupos minoritarios en condición de inmigración.

El trabajo está organizado en cuatro apartados: el primero da cuenta de los antecedentes de investigación. El segundo presenta el entramado teórico y metodológico de la investigación recuperando la discusión del cosmopolitismo y los derechos ciudadanos, y los aportes de la investigación cualitativa. El tercero presenta los resultados de la investigación a partir de la voz de nuestro protagonista y el juego de voces que se establece entre la investigadora y otros informantes clave. Finalmente, se presentan las conclusiones y algunos desafíos para futuras investigaciones a partir de las interrogantes que surgen como resultado de este trabajo.

\section{ANTECEDENTES}

En la última década, la investigación sobre procesos migratorios a los Estados Unidos se ha visto atravesada por la coyuntura política, social y económica entre México y el país del Norte. La literatura que aborda el tema adquiere un matiz político en torno al manejo migratorio, pues la agenda pública en torno al problema incide en la configuración de los objetivos y alcances de las investigaciones. La polarización de esta agenda política demanda que la academia asuma un posicionamiento ético y político con la investigación. Así, es importante considerar momentos de inflexión, como el Dream Act en 2006, el movimiento social Dreamer, el programa de Acción Diferida para los Llegados en la Infancia (DACA, por sus siglas en inglés), aprobado en 2012, el proyecto de Acción Diferida para Padres (DAPA) y la llegada de Donald Trump a la presidencia, en 2017.

En cuanto al programa DACA, una perspectiva transversal a los trabajos recogidos (Gonzáles y Terriquez, 2013, Gonzáles, Terriquez 
y Ruszczyk, 2014; Escobedo, 2016; Barros, 2017; Enríquez y Valdéz, 2018) es la defensa de los derechos civiles, políticos y educativos de la población migrante, la cual opera de forma subyacente en la narrativa de la mayoría de los trabajos de investigación. Sin embargo, aunque la perspectiva se da desde los derechos, las representaciones acerca del fenómeno de la migración no son homogéneas. Mientras Diaz-Strong y Meiners (2007) plantean un divisionismo al interior del grupo familiar, distinguiendo a la niñez y juventud migrante como "inocente", frente a los padres y madres de familia "culpables", que alguna vez decidieron migrar sin documentación legal, otros, como Lee (2015), prefieren poner énfasis en el conflicto sociocultural, económico y político que implica para las familias mexicanas migrar hacia el país fronterizo, entendiendo a todos los integrantes del grupo familiar como "ciudadanos en espera". El apoyo y visibilización de las necesidades de un programa destinado exclusivamente a madres y padres de familia, como la iniciativa del proyecto DAPA, da cuenta de la ruptura de la cadena de estigmatización hacia la población migrante adulta, presente en varios trabajos abordados en este apartado.

La mayoría de las investigaciones señaladas centran la narrativa principalmente en contextualizar el programa DACA y en distinguir los beneficios de su implementación, pese a que el programa no otorga un pase directo hacia la legalización del estatus migratorio. En este marco, se advierten dos momentos identificados con claridad. En el primero, se delimitan las condiciones sociopolíticas, económicas y culturales de producción, que dieron lugar a la emergencia del programa; se explicitan las peculiaridades y alcances del proyecto, los requisitos para la postulación y se estudian las características sociodemográficas del sector beneficiario. En el segundo se analiza el impacto del programa en la trayectoria de vida de los y las jóvenes migrantes, donde el ámbito educativo es un disparador para repensar y problematizar los alcances de los programas gubernamentales destinados a migrantes externos. Estas investigaciones presentan de manera transversal las pugnas entre la legislación estatal y federal y los programas de política pública emergentes en cada caso, ya que el DACA no se articula ni se aplica de forma homogénea en todo el país. Las investigaciones visibilizan en su narrativa esas 
pugnas de poder, donde se observa cómo la defensa del derecho a la educación de la niñez y juventud migrante es abordada por los gobiernos estatales de forma diversa y, por momentos, contradictoria, aun a expensas de la legislación federal.

Entre los medios para recuperar estos posicionamientos políticoideológicos y las condiciones de accesibilidad al DACA, destacan la técnica de entrevista y la observación. Se recuperan las percepciones y los sentidos que los sujetos asignan a las distintas instancias del programa, así como las ventajas de postularse en la configuración de trayectorias educativas y laborales significativas. Asimismo, se analizan los beneficios que reporta el que un miembro de la familia sea candidato o haya accedido al DACA para la movilidad social intrafamiliar.

El relato de vida construido a partir del método biográfico se presenta como una vía clara para indagar esos tránsitos, vaivenes, obstáculos, representaciones y desafíos que cruzan los sujetos que acceden al sistema educativo formal norteamericano, a través del DACA.

En la mayoría de las investigaciones recuperadas, el relato de vida y la delimitación de espacios geográficos van de la mano. Así, lugar de origen, de tránsito y de asentamiento terminan vinculándose con la elección de postular al DACA, una elección cruzada por condiciones político-pedagógicas muy variables. De ello, como señala Hernández-Hernández (2015), surge la relevancia de construir narrativas experienciales, con el fin de analizar significados y referentes estructurales, que configuran transversalmente las condiciones materiales y objetivas de existencia del sector migrante.

Relato de vida y relato de viaje coexisten en la mayoría de los trabajos, la trayectoria narrada dota de un sentido sociopolítico a cada espacio geográfico claramente delimitado. Los itinerarios migrantes son diversos. Si bien el inicio es similar en todos los casos -algún estado en México-, la trayectoria y, sobre todo, el espacio de arribo final, toman rumbos distintos. Así, en ocasiones llegan a estados fronterizos de ambos lados de la línea divisoria; en otras, trazan una trayectoria pendular, que inicia en México, va a la zona fronteriza y cierra en el mismo lugar de destino o cerca de ahí, ante la imposibilidad de cruzar la frontera. La deportación, por su parte, 
da inicio a un proceso de migración de retorno que aborda la mayoría de investigaciones de origen hispanohablante. En las circunstancias más adversas, por limitantes de orden socioeconómico que les impiden regresar hasta su lugar de origen, la frontera se configura como un "limbo legal", el único espacio geográfico disponible para asentarse, donde se les niega el acceso a un entramado de derechos básicos e inalienables, entre ellos, el derecho a una vivienda digna y a la educación.

En contraposición, los estudios de migración asentada en "espacios santuarios", son preponderantemente resultado de proyectos de investigación en lengua inglesa con subsidios de origen estadounidense y mexicano (véase Escobedo, 2016). En este contexto, Nueva York es, en varios relatos de vida, ese santuario de acogida, y toma en algunos trabajos (véase Santillanes, 2017) el tinte de paisaje de fondo y, en otros (véase Oliveira, 2017), una dimensión analítica que lo hace una categoría más de investigación para abordar la especificidad de la política pública migrante de ese estado y lo que implica en los itinerarios y las trayectorias educativas de los y las jóvenes migrantes.

De esta manera, el relato de vida da cuenta de las estrategias que los sujetos van desplegando para adaptarse al espacio al que llegan, así como de la experiencia y de las representaciones sobre las instancias de marginación y superación, entramando una narrativa de resistencia ante las políticas públicas migratorias. La experiencia biográfica se transforma así en un texto político, traducido desde la cotidianeidad del relato de viaje migrante.

En consecuencia, las investigaciones más recientes (Aupetit, 2017; Valle y Zepeda, 2017, Marín, 2018, Uribe, 2018) destacan la figura de Donald Trump como candidato republicano y como presidente y la consideran un hecho bisagra porque advierte el carácter restrictivo y xenófobo de la política pública migratoria. La administración Trump cruza las narrativas científicas y destaca la necesidad de articular investigación y contexto sociopolítico, lo cual se refleja incluso en las decisiones metodológico-epistémicas. De este modo, a diferencia de las investigaciones de corte cuantitativo de la década de los noventa, las investigaciones recientes se interesan por comprender la experiencia cotidiana de los sujetos en las instancias de 
migración, mediante el diseño de los instrumentos de investigación que asumen, en muchos casos, un posicionamiento desde el método biográfico y el análisis de percepciones y representaciones sociales. Asimismo, es destacable que las conclusiones se orienten hacia propuestas y sugerencias en materia legislativa, ancladas en la evidencia de las necesidades y demandas del sector migrante.

De este modo, se hace patente la necesidad de abrir espacios de investigación genuinos y arraigados a la realidad social en el campo académico, que incidan en la política pública y que planteen propuestas de salida ante una política de marginación y estigmatización.

\section{ENTRAMADO TEÓRICO-METODOLÓGICO}

En este apartado se problematiza el cosmopolitismo jurídico como una dimensión que se articula a la teoría del reconocimiento de Axel Honneth (2010), respecto al reconocimiento de la población en situación de exclusión, de las minorías étnicas y la población migrante como portadora de derechos. Para el autor, en el menosprecio hacia los individuos y las colectividades se observan prácticas de exclusión y de injusticia, lo que genera una desvalorización en la vida de las personas en las esferas afectivas y de los derechos.

De acuerdo con Honneth (2007), se pueden observar tres formas de reconocimiento: los lazos amorosos primarios que se construyen en la infancia y la amistad; el reconocimiento jurídico y de los derechos, y la solidaridad ante el otro y las colectividades. En las tres esferas de reconocimiento se observan procesos de exclusión e injusticia.

En el caso particular de la esfera jurídica y de los derechos, implica el reconocimiento del sujeto independientemente de su condición migratoria, género o raza. El reconocimiento del sujeto de derecho genera, a su vez, una serie de obligaciones que le permite construir un marco normativo e intersubjetivo en la vida social. De lo contrario el no-reconocimiento se convierte en una exclusión y, en mucho de los casos, en una lucha moral y política de los sujetos. Es decir, en una lucha por el reconocimiento.

En este sentido, el menosprecio a las personas, en particular al sujeto de derecho en condición migratoria, genera un agravio moral 
y una serie de injusticias en el plano jurídico, ético, político y social. Vivir sin derechos se convierte en la vida de los migrantes, en lo que Honneth (2009) llama las nuevas formas de sufrimiento social que propicia el capitalismo moderno, como un olvido o negación de las personas y las colectividades.

\section{El cosmopolitismo jurídico}

Acorde con el diccionario de lengua castellana, la palabra cosmopolitismo proviene de la palabra griega Kosmopolities, o ciudadano del mundo, y tiene su origen en la escuela de los estoicos, en lo particular, del filósofo griego Diógenes, con un estilo de vida austera, quien expulsado de su ciudad de origen recorría otras ciudades y se auto reconocía como ciudadano del mundo. El debate del cosmopolitismo no es, pues, una discusión reciente; se pueden encontrar algunas huellas discursivas en los griegos, en el pensamiento ilustrado de Kant (2013) y actualmente con Nussbaum (1994) quien problematiza acerca del patriotismo y el cosmopolitismo en los Estados Unidos, y provocó un gran debate acerca de la educación ciudadana que deberían recibir los estadunidenses, más allá de los ideales del patriotismo norteamericano.

Una obra clave del discurso del cosmopolitismo, es la llamada Pazperpetua, de Kant (2013), al introducir la noción de estado cosmopolita, del derecho de la ciudadanía mundial a la hospitalidad universal regulada por una constitución política fundamentada en la libertad y la igualdad de todos, pero con dependencia -como súbditos- de la legislación. Para el autor, la regulación de los súbditos por medio del contrato originario resulta necesaria para la paz perpetua.

El cosmopolitismo kantiano plantea el derecho natural de todo hombre a vivir en cualquier lugar del mundo, de ser ciudadano cosmopolita y recibir un trato de acuerdo con los derechos de la ciudadanía mundial y de una universal hospitalidad. La noción de hospitalidad resulta central para el ciudadano cosmopolita e implica el reconocimiento de la otredad, la extranjería, de recibir un trato amigable y no ser menospreciado.

La Paz perpetua representa un punto de referencia y base de la discusión jurídica, política y ética del derecho a la educación de 
la población migrante. El pensamiento kantiano ha sido fuente de inspiración para el surgimiento de organismos internacionales como la ONU-UNESCO, de los discursos de los derechos humanos y del derecho a la educación para la formación del ciudadano.

La tendencia del cosmopolitismo y los derechos humanos se ha expresado en la producción de la teoría jurídica referida a las reformas de instituciones públicas mundiales (cosmopolitismo institucional) y de tribunales de justicia global (cosmopolitismo jurídico) sostenidos e impulsados por el discurso del derecho institucional. El cosmopolitismo institucional está fuertemente anclado a los organismos internacionales vía la carta de las Naciones Unidas (1945), la Declaración de los Derechos Humanos (1948) y los Pactos de Derechos (1966), textos que son resignificados como parte de una constitución en el orden mundial.

Es de llamar la atención el conocido como cosmopolitismo alterno, articulado a los movimientos sociales globales, a los movimientos emergentes, resultado de la globalización, como el de los inmigrantes. De acuerdo con De Sousa (2009) estos movimientos erosionan la soberanía territorial al re-ocupar territorios donde son tolerados y permitidos bajo el estatuto jurídico de los derechos humanos y, al mismo tiempo, generan procesos de exclusión ante la extranjería, menosprecio y discriminación, lo cual resulta contradictorio frente al discurso del cosmopolitismo jurídico debido a la prioridad que se otorga a la soberanía nacional de los países.

En síntesis, la mirada de Honneth (2007, 2009 y 2010) acerca de las esferas del reconocimiento, en particular de los derechos humanos permiten potenciar los acuerdos internacionales acerca de los inmigrantes y sus derechos, como el derecho de recibir un trato digno independientemente de su condición migratoria y otros derechos, entre ellos el de la educación. En este debate, el cosmopolitismo jurídico y el cosmopolitismo alterno juegan un papel fundamental en la defensa de los derechos de los migrantes ante las cortes estatales, nacionales e internacionales. 


\section{La mirada cualitativa}

Este trabajo se inscribe en los principios del paradigma interpretativo y busca la comprensión de los fenómenos sociales. Se trata de una teoría naturalista presentada de forma narrativa, en lugar de una teoría formal presentada en forma "proposicional" (Elliot, 1991, p. 25). Para suplantar los esfuerzos por descubrir e interpretar la realidad, en la metodología cualitativa, Gergen y Gergen (2000), se plantean innovaciones metodológicas y se delinea la reflexión y las voces múltiples, la primera hace referencia a la voz del investigador en el análisis de una situación. La segunda, a la eliminación de la única voz del investigador, virado por la importancia de incluir las diferentes voces de los participantes.

Es importante señalar que otra de las actualizaciones del método cualitativo es la de cambiar la palabra re/search por la de re/present; de esta forma, aquellos que son sujetos de investigación y los lectores se vuelven participantes, relacionándose entre sí mediante una narrativa participativa. El objetivo tradicional de la investigación, que es el de acumular productos, se cambia por el de generar procesos comunicativos, empezando por buscar formas más productivas y colaborativas en la investigación educativa. En esta investigación, se decidió realizar un caso único (Stake, 2005), la narrativa de Angelo Cabrera, porque permitió aproximarnos de manera paulatina y a profundidad a cómo han sucedido los hechos y lo que puede aportar para el entendimiento de un fenómeno; en este caso, el derecho a la educación en contextos migratorios.

Entre las técnicas seleccionadas nos apoyamos en el diario de campo, la entrevista a profundidad, los diálogos continuos con nuestro informante en su entorno social, laboral y de esparcimiento, con el objeto de comprender el tejido narrativo que va construyendo a lo largo de su trayectoria escolar y de vida como defensor del derecho a la educación. Además, de entrevistas a otros informantes clave.

Durante cuatro meses se realizaron entrevistas a profundidad y diálogos informales con Angelo Cabrera en diferentes encuentros en la Universidad de la Ciudad de Nueva York (CUNY-Baruch College), ubicada en la gran manzana de Manhattan, en su contexto social y familiar ubicado en Queens. Esto permitió crear un clima de trabajo 
y empatía con nuestro protagonista en una investigación colaborativa. Cada una de las entrevistas fue transcrita inmediatamente ya que representaba el insumo principal para iniciar la siguiente entrevista. Posteriormente, se identificaron los micro-relatos presentes a lo largo de las entrevistas y con esta información se construyeron categorías intermedias y etnográficas para dar inicio a la narrativa de la trayectoria escolar y de vida de Angelo Cabrera.

Entre las categorías cabe destacar las siguientes:

- Mi familia, mi pueblo y la migración a los Estados Unidos.

- La vida de migrante en Nueva York: trabajar y trabajar; trabajar y estudiar.

- Siempre quise estudiar incluso en México.

- Yo estudié hasta la secundaria en México, iba a cumplir 15 años cuando migré.

- Descubrí que un indocumentado puede estudiar.

- Mi inglés era muy limitado.

- Saber navegar en el sistema.

- MASA como club de estudiantes en el Fall de 2001.

- El liderazgo en la lucha política por el derecho a la educación.

Finalmente, se dio inicio a la narrativa de Angelo Cabrera, con especial énfasis en la constitución de sujeto de derecho y la lucha por el derecho a la educación superior. El primer borrador de la narrativa escrita fue compartido con nuestro protagonista, tal como lo señala la investigación cualitativa, devolver y de-construir el propio relato con nuestro entrevistado, con la finalidad de realizar las precisiones y cambios necesarios. En este caso, exaltar la voz del protagonista, precisar las fechas, la escritura en inglés y español y ampliar los temas que quedaron excluidos por quien acompañó el relato y que resultaron significativos para nuestro protagonista. Con la finalidad de dar a conocer los primeros resultados de la investigación, en este trabajo se recuperan algunas de las categorías que permiten dar cuenta de la trayectoria escolar y de vida de nuestro protagonista. Cabe señalar que, al finalizar las entrevistas y con el resultado de este primer texto, se decidió, de manera conjunta entre Angelo, su mentor académico de la Universidad de la Ciudad de Nueva York 
y quien acompañó este relato, que el protagonista es quien debe contar su propia historia con el insumo de las entrevistas a manera de autobiografía. En este sentido, la discusión de la ética y responsabilidad en la investigación educativa vuelve a hacer resonancia por el papel que le corresponde a cada uno.

\section{RESULTADOS}

En este apartado se presenta la narrativa de nuestro protagonista a la manera de juego de voces desplegada a lo largo de las entrevistas, los diálogos informales con Angelo y otros informantes clave.

\section{Ser joven, migrante e indocumentado}

Angelo Cabrera es originario del estado de Puebla, y migró a los Estados Unidos a la edad de 15 ańos, como una alternativa de vida para enfrentar la pobreza económica de su familia, aunada a los conflictos partidarios en su comunidad y al enfrentamiento entre las familias. $\mathrm{Al}$ referirse a su pueblo, lo primero que recuerda es el desprecio que vivió desde temprana edad por parte de sus familiares y de la propia comunidad por no pertenecer a una familia de ejidatarios. "Me convertí en un niño rebelde". De acuerdo a Honneth (2010), la primera forma de reconocimiento se experimenta a través de los lazos sociales (afectivos), en este caso de la familia y el entorno social comunitario. Angelo alude, de manera reiterada, al deprecio hacia su persona tanto en la nińez, cuanto como migrante, en particular por el color de su piel.

A lo largo de su narrativa hace un recuento de sus vicisitudes y experiencias de vida para ingresar a los Estados Unidos, entre ellas, estar "varado" un año en Tijuana, México; vivir en condiciones paupérrimas, en sus propias palabras, "como homeless"; trabajar en la artesanía del ónix para juntar un poco de dinero; regresar nuevamente a su pueblo y realizar los acuerdos para intentar cruzar la frontera por segunda ocasión.

Hubo momentos en que no tenía para comer en Tijuana y había un señor al que le pedí trabajo para poder comer algo y recuerdo que 
lo único que tenía eran mangos que estaban tirados... pues yo me senté y empecé a comer, nunca me había sentido tan espectacular, con una vista hermosa (E/AC).

Angelo invoca el manjar de mangos como una metáfora para dar cuenta de la vida de migrante y joven desterrado de su pueblo natal por la pobreza, los conflictos partidarios y altercados entre las familias. Él ingresa a los Estados Unidos vía Tijuana, México, al estado de California y posteriormente viaja a través de la aerolínea Panam a la ciudad de Nueva York, con el apoyo de su primo, quien pagó a un "coyote" para traerlo. "Bueno pues, la historia de ahí empieza, pues uno llega muy joven, de 15 años".

En la década de los noventa, época en la que llegó a vivir al barrio del Bronx, la zona era considerada conflictiva por la presencia de las pandillas, la venta de drogas y el asalto a los trabajadores e inmigrantes mexicanos, en palabras de Angelo, el Mexican hunting. Él caminaba por las noches con miedo, porque estaba de moda cazar a los mexicanos a la salida del tren. Para evitar ser asaltado trataba de asimilar la cultura, la forma de vestir y actuar como los jóvenes del barrio. Se dirigía a las pandillas con un pequeño saludo: What's up? What ya doing? What's cooking? De esa manera intentaba pasar desapercibido y con eso evitaba que lo asaltaran. Aunque, en sus propias palabras "era difícil interactuar, vivir con miedo de que te vayan a robar. Cuando salía más tarde dividía mi dinero en partes”.

$\mathrm{Su}$ trayecto laboral se convirtió en un verdadero viacrucis porque, además de ser menor de edad, era muy debilucho "aquí tienes que trabajar, tienes que pagar la renta, tienes que pagar el dinero que usaron para traerte". El abuso y la explotación a la que se vio sometido en los múltiples trabajos, pasando por la industria de la construcción, la limpieza de cines, supermercados, fruterías y restaurantes, hizo erosión cuando fue encerrado en un basement durante el día, del que logró escapar y caminar sin rumbo del Bronx hacia Manhattan para solicitar ayuda. En el camino se encontró con una joven sudcoreana: "le dije, con el poco inglés, que estaba buscando trabajo y me llevó al lugar donde ella trabajaba”. La joven sudcoreana era estudiante migrante internacional, lo auxilió para buscar un trabajo y lo apoyó para presentar el examen del GED (equivalencia 
del bachillerato), lo cual le generó una fuente de admiración e inspiración para luchar por su ingreso a la universidad.

Al respecto, la teoría del reconocimiento señala que el sujeto vive una desvalorización, cuando no tiene un estatus de derechos ciudadanos, tal como lo plantea la promulgación de los derechos humanos y los tratados de los derechos de los migrantes, de recibir un trato digno como persona y trabajador. La joven sudcoreana reconoció la diferencia del otro inmigrante. Para Honneth (2010), el reconocimiento de las personas y las colectividades es un aspecto central de la justicia.

\section{Yo estudié hasta la secundaria en México, iba cumplir 15 años cuando migré}

A lo largo de la narrativa de Angelo Cabrera, el imaginario de la escuela y el valor por la educación siempre estuvieron presentes. Él recuerda el interés por asistir a la escuela desde temprana edad "pues yo siempre quería estudiar, desde México quería estudiar, para mí la educación es muy importante". Sin embargo, la situación económica lo "empujó" a migrar a los Estados Unidos. La remembranza de su trayectoria escolar, como efecto de introversión, hizo que recordara su primera experiencia en la escuela a la edad de tres ańos, cuando lo aceptaron como oyente en la primaria, al momento de inscribir a su hermano en la escuela de su pueblo. "Me gradué a temprana edad como uno o dos años antes y aprendí a leer muy temprano”.

La evocación a los centros escolares de su pueblo, tanto de la primaria como de la telesecundaria, atraviesan la distinción de la clase social, de pertenencia y, por ende, su inserción al trabajo infantil, al que fue obligado con la intención de apoyar sus estudios y a su familia. Sus padres no eran ejidatarios y su mamá tenía que trabajar en la venta y trueque de los productos para la alimentación de la familia y de sus abuelos paternos. Además, él la acompañaba al mercado para vender y hacía diferentes servicios para ganarse algo de dinero y comprar los útiles escolares o cualquier cosa que necesitaba para la escuela. "Trabajaba para pagarme mis propios pasajes y mi mamá a veces me ayudaba. Por lo regular, yo solo me cubría mis necesidades".

Angelo estudió la primaria en su pueblo natal y desde pequeño lo combinó con el trabajo. Entre los recuerdos que le vienen a la 
cabeza, se refiere a la edad temprana a la que asistió a la escuela; el aprender a leer desde pequeño y sin dificultades, a diferencia de su hermano que no concluyó la educación primaria. "Llegué hasta tercer año como oyente, porque no me podía registrar. Pero yo ya podía leer y escribir". Por ese motivo, se graduó a temprana edad. Como él mismo lo manifiesta, tenía un gran interés por continuar con sus estudios y empezó a buscar otras alternativas dado que en su pueblo sólo había una telesecundaria.

Cabrera prefirió estudiar la secundaria en la ciudad más cercana, ya que consideraba que le ofrecía más oportunidades para "salir adelante”. Para Angelo, la telesecundaria tenía un menor valor, dado que sólo contaba con un maestro para todos los grupos y una televisión que tenía que estar viendo. Esto da cuenta de las opciones educativas de las comunidades ruralesy de las condiciones en que se imparte la enseñanza.

A Cabrera le hubiera gustado estudiar en la Secundaria Federal II, ya que tenía más estatus que la Secundaria para Trabajadores a la que asistió:

Yo iba a la Secundaria para Trabajadores, después estaba la Federal II, la Técnica y la L. Tamayo, [que era] más exclusiva, los papás llevaban a sus hijos en carro...la Secundaria para Trabajadores estaba más afuera de la ciudad, [iban] chicos banda, de bajos recursos, los que no quedaron en otras secundarias ...era de más baja categoría ...había un grupo de niñas de orfanatos ...no teníamos talleres, simplemente las clases y la música (E/AC).

Es de llamar la atención la decisión que llevó a Angelo a asistir a la escuela fuera de su lugar de origen y viajar a la ciudad para estudiar en una Secundaria para Trabajadores, clasificada por él mismo de más baja categoría, como lo hizo también con la telesecundaria de su pueblo. De la secundaria recuerda la burla de sus compańeros por traer un morral y lo importante que se sintió al momento de comprarse un suitcase, en el segundo año de la secundaria, lo que le daba más estatus y lo hacía sentirse importante.

A lo largo de sus estudios de nivel básico (primaria y secundaria), Angelo atravesó las barreras del acceso, la permanencia y el 
logro educativo como parte de una comunidad rural pobre a través de la combinación del trabajo y el estudio desde temprana edad. En este sentido, el valor otorgado a la educación le posibilitó continuar sus estudios independientemente de las condiciones económicas y la escasa o nula escolaridad de su familia. Su narrativa muestra la diversidad de servicios educativos del subsistema de educación básica como la Secundaria General, la Secundaria Técnica, la Secundaria para Trabajadores, la Telesecundaria y otras de este nivel educativo.

\section{Descubrí que un indocumentado puede estudiar}

El nombre de Angelo Cabrera fue registrado en el sistema educativo de la ciudad de Nueva York, en el instante que su amiga, la sudcoreana, le pagó la inscripción de las clases para presentar el examen del GED (General Education Development), equivalente a los estudios de preparatoria o High School. Hasta ese momento, él era Ángel Cabrera, su inscripción de Angelo en la boleta de pago le gustó y lo adoptó como su nombre y pasó de ser Ángel a Angelo, como él mismo lo señala, "es mi nombre artístico".

Con el pago de su inscripción por parte de su amiga y el apoyo de 280 dólares para tomar clases y presentar el examen del GED, Angelo se dio a la tarea de estudiar para poder acreditar el bachillerato, en sus propias palabras, su amiga fue su gran inspiración: "ella trabajaba sábados y domingos. Nos hicimos amigos y siempre le preguntaba de la universidad, que quería estudiar. Un día me llevó un sobre con el dinero y ya con el registro del College y me dijo 've el próximo sábado"'. El reconocimiento como persona le permitió ir construyendo la identidad de sujeto de derecho, del derecho a la educación, independientemente de su situación migrante, con papeles o sin papeles tenía derecho a estudiar. "Para mí fue muy emocional... no sabía qué decir... me puse a llorar". En palabras de su mentor, académico de la Universidad de la Ciudad de Nueva York: "Angelo tenía un gran deseo de estudiar para ayudar a otros mexicanos".

Con el mandato de su amiga, la coreana, de ayudar a otros como lo hicieron con él, en la memoria de nuestro protagonista quedaron registradas las palabras de ella "'cuando llegues a la universidad, abre 
las puertas para ayudar a otros' ...y trato de hacer lo que corresponde". Cabrera se dedicó a estudiar para presentar el examen y acreditarlo sin problema, aunque reconoce que en el idioma inglés era muy limitado, enfrentó ese reto cuando decidió ingresar a la universidad y estudiar una carrera técnica en computación. "Me puse a estudiar, estaba $100 \%$ concentrado al estudio. Iba a estudiar por las noches y después del trabajo y los sábados [también], que era mi único descanso". El trabajo y el estudio se convirtieron en la ruta que construyó para aferrarse al deseo de estudiar "me iba a estudiar mi High School, mi GED, mi prepa abierta, era entre 1995 y 1996, no recuerdo bien".

De acuerdo con su narrativa, el examen del GED fue de conocimientos básicos de matemáticas, español, literatura, ciencias, historia y "al final un examen de inglés para saber mi nivel”. A lo largo de nueve meses se preparó para acreditar el examen y puso especial atención al aprendizaje del inglés e incluso se inscribió a la academia American Language Center, "entonces para mí era hablar a toda costa y con cualquier persona”. En ese tiempo trabajaba en el Deli preparando ensaladas y les hablaba a sus compañeros en inglés y hacía acuerdos con ellos "al final, ellos se las ingeniaron para hablar inglés, como el aprender a saludar, cómo preparar los alimentos y saber preguntar qué otra cosa quieren”.

Con el certificado del GED, Angelo sabía que podía ingresar a la universidad, pero no sabía cómo y decidió preguntar en las oficinas administrativas de la Universidad de la Ciudad de Nueva York (CUNY). Un requisito fundamental era contar con el número del seguro social, que únicamente lo tienen los ciudadanos y residentes de la ciudad. "Yo simplemente dije-Quiero estudiar, ¿cuáles son los requisitos? ... pero quiero estudiar. ‘¿Cómo vas a pagar?' 'No sé'. Fue tanta mi insistencia que me dijo 'Bueno, tráeme tus papeles”'.

\section{Saber navegar en el sistema}

Angelo Cabrera logró inscribirse en la Universidad con el número de cuenta escolar como su número de seguro social y por primera vez empezó a visualizar un path, un camino que no hubiera imaginado sin el apoyo de su amiga la sudcoreana y la administradora que, ante 
su insistencia, lo inscribió a una carrera en Técnico en Programación de Computación, después cursó dos años Ciencias de la Computación, la licenciatura en Ciencias Políticas y una maestría en Política Pública.

A Cabrera le llevó 15 años realizar sus estudios desde la carrera técnica hasta la maestría. En 1998 ingresó al Community College y para 2013 logró concluir sus estudios de posgrado en plena efervescencia de cambios radicales en el estado de Nueva York y en general en los Estados Unidos. El atentado terrorista del 11 de septiembre (conocido como 9/11 en ese país), con el derribamiento de las Torres Gemelas, generó una política anti migratoria y fue un parteaguas en la vida de los ciudadanos americanos, pero también de los estudiantes universitarios migrantes, muchos de los cuales fueron excluidos del sistema escolar universitario.

Saber "navegar en el sistema" representó la estrategia de sobrevivencia de Cabrera en el de educación superior, desde la exigencia de su registro universitario, de contar con un lugar en la universidad, hasta la exigibilidad y justiciabilidad del derecho a la educación para los jóvenes universitarios migrantes afectados por la política escolar posterior al 9/11. A partir de su registro en la universidad utilizó el mismo número cuando se registró en la licenciatura y maestría.

A lo largo de esta lucha, en palabras de Cabrera, se sintió entitled, con derecho legal. "Una persona que estaba ahí me ayudó a llenar la solicitud y desde ahí, a estudiar”. Para el protagonista no era común que un estudiante sin documentos quisiera estudiar. Al llegar a los Estados Unidos, la gente únicamente viene a trabajar para ayudar a la familia, como era su objetivo, trabajar y enviar dinero a sus papás. Esta situación le ayudó a empoderarse como sujeto de derecho y, al mismo tiempo, a sentirse excluido por ser migrante. Saber navegar en el sistema le resultó revelador, porque en la universidad nadie le preguntó si tenía documentos legales o no.

Ahora, el rechazo lo tenía de su propia comunidad "mucha gente, a mi alrededor, se burlaba de mí... me trataban como loco y me decían 'para qué quiere estudiar un indocumentado', me ponía a llorar, me excluían”. A pesar de las burlas, Angelo ingresó al Baruch Manhattan Community College y se graduó en Técnico en Programación en Computación y de allí se transfirió a la Universidad de 
CUNY/Baruch con el deseo de estudiar su Bachelor's en ciencias de la computación y beneficiarse económicamente por lo rentable de esa carrera. Sin embargo, la vida lo llevó por otro sendero ante el movimiento que se generó con el pago de colegiaturas bajo la norma Fuera del estado para los estudiantes migrantes, esto lo llevó a cambiar su ideología y enfocarse a estudiar Ciencias Políticas y después Política Pública.

Una vez que ingresó a la universidad, empezó a promover el acceso de otros jóvenes mexicanos a los estudios universitarios y articuló esfuerzos con la Universidad de CUNY, el Consulado Mexicano, académicos, redes y organizaciones comunitarias. Además, empezó a dar clases de alfabetización con personas adultas de la comunidad mexicana en el Bronx y se convirtió en uno de los portadores del movimiento de los estudiantes migrantes por el pago de colegiatura Fuera del estado. "Era una forma de re-encontrarme conmigo mismo".

\section{La lucha por el derecho a la educación superior}

Angelo Cabrera vivió y fue activista en diversas manifestaciones en pro de los migrantes mexicanos en su lucha por el derecho a la educación, entre ellos el movimiento de los Dreamers a nivel nacional, la presión política para la Dream Act, el apoyo a los jóvenes mexicanos para aplicar al programa Deferred Action for Childhood Arrivals (DACA), el movimiento estudiantil que se generó por la política anti migratoria como una respuesta al acontecimiento del 9/11 y el cambio jurídico en la ley del estado de Nueva York por el In-State Tuition que alude al pago en las universidades. Angelo se convirtió en líder estudiantil para protestar y organizar los procesos de exigibilidad social y justiciabilidad para el cambio jurídico a través de una huelga de hambre y otras acciones políticas, entre ellas, "salir de la sombra". Al respecto, Honneth (2009) señala que la esfera de los derechos y de la solidaridad son expresiones de la lucha por el reconocimiento de las personas y las colectividades.

Con el poderío como sujeto de derecho y el capital escolar que fue construyendo a lo largo de su trayectoria escolar, Angelo conformó un grupo de apoyo, un task force. Entre ellos su profesor de sociología y experto en migración de la Universidad de CUNY-Ba- 
ruch, con más de 30 años realizando etnografías de la comunidad mexicana en los Estados Unidos. Además de otras redes sociales y organizaciones comunitarias, entre ellas, el Consulado Mexicano (Smith, 2006).

Con la creación del grupo de apoyo, entre ellos su mentor y amigo, Cabrera empezó a realizar diversas acciones para promover el derecho de los jóvenes de ingresar a la universidad, él recuerda el evento en el Consulado Mexicano en 1997, se convirtió en spokesman, vocero de la comunidad mexicana para promover el acceso universitario a otros jóvenes. "Me presenté como estudiante universitario indocumentado... comenté que sí se podía estudiar y que yo apoyaba a otros estudiantes para su ingreso a la universidad. Al evento llegaron más de 500 personas, además de jóvenes mexicanos, de otros países, como de Polonia”. En el consulado estaban incrédulos y tuvieron que sacar los speakers, los altavoces, para que pudiera dirigirse a los jóvenes. Angelo se sintió emocionado por el interés avivado entre los jóvenes. Con esta acción, la construcción de agencia potenció su liderazgo.

De acuerdo a la narrativa de Cabrera, con el derribo de las Torres Gemelas el 9/11 se cambió la política hacia los estudiantes universitarios migrantes y sin visa. La universidad les envió una carta para informar la fecha en que pagarían su colegiatura como estudiantes Fuera del estado de Nueva York. Es decir, como estudiantes extranjeros. "Ya estaba estudiando y fue después del Thanksgiving que nos enviaron la carta. Muchos indocumentados amigos míos...fue como un shock, algo muy duro, heartbreaking, le llamamos acá. Ellos tenían que pagar dos o tres veces más". A Cabrera nunca le enviaron la carta y ante ese hecho decidió protestar de manera conjunta con otros líderes y representantes de organizaciones como un acto de discriminación de la universidad contra sus compañeros estudiantes migrantes como él.

De manera conjunta con Casa México, Cabrera inició la lucha para erradicar esa ley, con una legislación que beneficiara a los estudiantes migrantes en Nueva York, para que pagaran como residentes americanos, el llamado In-State Tuition o colegiatura del estado. Durante esas fechas tras el ataque terrorista del 9/11, en el estado de Texas emergía otro movimiento de la misma naturaleza que en 
Nueva York "estábamos en medio de protestas ....allá se pasó primero y después en NY y se adhirieron 18 estados al In-State-Tuition y de manera reciente en el estado de New Jersey".

La remembranza de Angelo, durante ese periodo, fue la huelga de hambre que realizó durante tres días con otros estudiantes. Además del cabildeo con políticos de primer nivel, las protestas masivas y el cambio jurídico. Cabrera salió de la sombra y descubrió su liderazgo nato, sensible a la problemática de sus amigos estudiantes migrantes y demandó a la universidad a partir de su propia situación e historia de vida. A él no le llegó la carta y no le aplicaron el pago de colegiatura Fuera del estado. Como él mismo lo señala, se convirtió en spokesperson, era uno de los estudiantes que salió de la sombra.

El caso de Angelo Cabrera llamó la atención a los medios periodísticos a partir de la huelga de hambre durante tres días y de su historia como estudiante migrante. "Porque a pesar de que era un estudiante indocumentado, la universidad no me penalizó a mí ... era la voz del programa diciéndole al sistema que a mí me trataban diferente y a los demás indocumentados los trataban de otra manera”. La acción directa del activismo y el liderazgo de Cabrera empezó a tomar mayor fuerza y presencia pública con la aprobación de la ley en agosto de 2002. Después se incorporó al movimiento de los dreamers que surgió a raíz de la lucha por el In-State Tuition a nivel nacional y, posteriormente, enfocó su lucha por la educación en el estado de Nueva York, con la gestación de un club de estudiantes inicialmente llamado Mexican American Students Alliance (MASA), para protestar y organizar el movimiento universitario al rechazo de pago de colegiaturas a los estudiantes migrantes como fuera del estado.

\section{MASA como club de estudiantes}

Con el ingreso de Angelo a la Universidad y su acción político-pedagógica con los jóvenes migrantes a partir de los talleres informativos, Cabrera empezó a organizar, en 2001, un club de estudiantes articulando esfuerzos con la universidad de CUNY, organizaciones y grupos de apoyo a las minorías, con la finalidad de realizar acciones conjuntas dirigidas a los estudiantes afectados por el pago de colegiatura. Con el cambio de la Ley 
en el estado de Nueva York, el club de estudiantes orientó su quehacer político-pedagógico y empezó a apoyar a los jóvenes del High School, a partir de sus propias necesidades y demandas académicas en la institución escolar. Es de llamar la atención la forma en que Cabrera y la Alianza de Estudiantes México-americanos apoyaron a los jóvenes de la comunidad mexicana para su ingreso a la universidad. De alguna manera significaba compartir sus conocimientos de "saber navegar en el sistema", a partir de su propia experiencia en la universidad. La mentoría se convirtió en la estrategia político-pedagógica para dar acompañamiento a otros jóvenes, con atención personalizada, uno a uno, a partir de las necesidades de los estudiantes. Se conversaba acerca de la universidad, de cómo enfrentaron y resolvieron sus problemas académicos "simplemente éramos mentores. Hablar con ellos de la universidad. ¿Cómo le hicimos? ¿Cómo pueden llegar a la Universidad? ¿Qué necesitan saber? ¿Cómo hacer un ensayo? Hablábamos y lo hacíamos".

En los orígenes de MASA, no existía una estructura, una organización administrativa, simplemente "era trabajo voluntario, había necesidades y las atendíamos”. El trabajo se enfocó más a la atención de los jóvenes estudiantes y actualmente cuenta con un programa dirigido a la educación de los niños que recién inician su trayectoria escolar, con la finalidad de acompañarlos y atender sus necesidades escolares.

A lo largo del tiempo muchos de los jóvenes que pasaron por MASA cuentan con estudios universitarios y son líderes de organizaciones comunitarias o bien trabajan con políticos en la toma de decisiones. Tal es el caso de María, beneficiaria del DACA, quien colaboró en el área educativa en el Consulado Mexicano, y actualmente realiza investigación de manera conjunta con Angelo, bajo la dirección de su mentor y amigo de CUNY-Baruch, acerca de los beneficios del DACA y de los llamados dacamentados.

Angelo estuvo al frente de MASA durante más de una década, lo que le permitió buscar alianzas y acuerdos con las instituciones educativas locales, como el Departamento de Educación de la ciudad de Nueva York, para colaborar en pro del derecho a la educación en la primera infancia, el preescolar y la universidad. Actualmente, promueve una escuela de doble inmersión (español e inglés), considerada una escuela chárter dirigida a los jóvenes de High School que recién migraron a los Estados Unidos. De la misma forma, continúa 
promoviendo los talleres informativos para el ingreso de los jóvenes a la universidad de CUNY, independientemente de sus condiciones migratorias.

\section{Saberes y aprendizajes sociales en contextos migratorios}

A lo largo de la narrativa de Angelo Cabrera se despliegan los saberes y los aprendizajes sociales que le permitieron configurarse como sujeto de derecho, entre ellos, aprender a navegar en el sistema desde la clandestinidad, por su estatus legal, y saber que las barreras existen o se multiplican por esa razón: "simplemente aplicas y pides acceso a este servicio [la educación universitaria] sabiendo que te lo van a negar ... te da un sentido de vida de que no importas". En palabras de Honneth (2010), no se le reconoce como persona y menos como sujeto de derechos en las áreas de salud, educación y trabajo digno.

De igual forma, se van desplegando diversos sentidos acerca de los saberes y aprendizajes sociales vinculados a "saber navegar en el sistema”. Esto involucra la búsqueda de información, investigar, preguntar o simplemente buscar ayuda de un profesor, del consejero universitario o a una persona que ya caminó por el mismo proceso. Pero, sobre todo, atravesar las barreras individuales y deconstruir la construcción social acerca de los derechos de los migrantes. "Dejar a un lado la creencia, la assumption, la creencia errónea de que no tienes acceso porque eres un indocumentado. Desde creer en ese contexto, que no puedes por ser indocumentado y empiezas a crear [tú mismo] una serie de barreras”. Además, deconstruir la construcción social de las prácticas sociales con la población migrante relacionadas con el racismo y la discriminación.

Entre los aprendizajes sociales vinculados al activismo político resulta fundamental conocer a la persona adecuada, aquella que tiene el poder en la toma de decisiones y que puede cambiar las cosas al conocer la vida de otras personas, tal como él lo experimentó al contar su historia y salir de la sombra para ser reconocido como sujeto de derecho y como integrante de una comunidad estudiantil que lucha por sus sueños. "De que la hemos pasado duro y logramos conseguir un sueño académico. Siempre digo, mis tragedias son mi inspiración. My tragedies are my own inspiration to overcome my struggles." 
Saber navegar en el sistema requiere estar abierto al conocimiento y al desarrollo de capacidades, entre las que se incluye el contar historias -la de Angelo y los dreamers- "Story telling, estudié en Harvard acerca de la historia del yo, de nosotros y la acción”. Al igual, realizó estudios de Mapping que le ayudaron para realizar un censo de la población mexicana en Nueva York; un curso de escritura periodística, para enviar la nota a los diarios acerca de los acontecimientos del movimiento universitario y de los dreamers. En síntesis, el activismo político lo llevó a buscar y tomar las oportunidades de estudiar acerca del trabajo en comunidad, elaboración de volantes, hablar en público, dirigirse a las personas, cabildeo, presionar por medio de la huelga de hambre para impulsar el cambio jurídico, con press releases, speaches. Asimismo, iniciar otro tipo de narrativas a través de la construcción de redes y el uso de las tecnologías de la información; pero, sobre todo, aprender a escuchar a las personas, con un respeto mutuo para el cambio y la defensa de los derechos, en particular del derecho a la educación superior y la atención a los niños y jóvenes. "Siempre teniendo en mente que el dolor, las tragedias y las necesidades son fuente siempre de mi inspiración. De mis cambios de vida. Eso me lleva a tomar la acción”.

Cabrera se considera generación 1.5, numeración acuñada por el investigador en estudios migratorios de la Universidad de California, Rubén Rumbaut (2006), para dar cuenta de la población infantil que migró ilegalmente con sus padres a los Estados Unidos. La generación 1.5 fue socializada escolarmente en los Estados Unidos, hablan inglés y no cuentan con documentos migratorios. En el caso de Angelo Cabrera, migró a los Estados Unidos a la edad de 15 años y la educación básica (primaria y secundaria) la realizó en México, a diferencia de los niños que migran muy pequeños acompañando a sus padres.

El paso de Angelo por la universidad de CUNY y la acreditación del examen del GED, fueron aspectos fundantes para la construcción de su identidad como sujeto de derecho y, con ello, de su acción política en defensa del derecho a la educación superior. Sin duda, su curso por la licenciatura en Ciencias Políticas y la maestría en Política Pública, más la carrera técnica en Computación y los primeros grados en Ciencias de la Computación le permitieron irse enalteciendo 
acerca de sus derechos para desmantelar "la creencia errónea de que no tienes acceso porque eres un indocumentado" y, por ende, no tienes derechos.

Por ese motivo, Cabrera aprendió a valorar sus derechos sin importar el estatus legal "yo puedo exigir mis derechos", a partir de su ingreso a la universidad y el conocimiento logrado por medio de las carreras acerca de la política en el estado de Nueva York. Esto le dio la oportunidad de aprender y de convertirse en sujeto de derecho, que puede exigir social y jurídicamente, tal como lo plantea el derecho a la educación con relación a la exigibilidad y la justiciabilidad; aunado al capital escolar que construyó en la universidad y en el activismo político, además de los cursos formales e informales, a distancia o presenciales.

Como generación 1.5, Cabrera se diferencia de la primera generación, a la cual también pertenece por ser el primero de la familia en ingresar a los Estados Unidos, con el sueńo de trabajar y enviar dinero a sus padres. En su narrativa marca una diferencia en la identidad "como migrante generación 1.5, tenemos acceso a la educación, podemos crear un cambio a través de la educación de futuras generaciones. Pero también de la generación adulta”. La generación 1.5 se considera favorecida del Programa de Acción Diferida, aunque como lo planteó María, beneficiaria del programa DACA, "es como un curita puesto a una herida". No es una verdadera reforma migratoria.

La lucha por la defensa del derecho a la educación de los jóvenes migrantes se convirtió en la bandera de Cabrera como activista político. Al respecto argumentó que, cuando empezó a trabajar con los mexicanos, advirtió la importancia de abrir espacios a otras generaciones, a las futuras generaciones. Por ejemplo, a los "dreamers ... estos chicos ya están trabajando con políticos, haciendo campañas políticas, en la arena política; por eso tenemos que abrir espacios". En la narrativa de Angelo, la lucha por el derecho a la educación lo lleva a fundar la organización MASA, para crear liderazgo entre los jóvenes mexicanos y luchar por el derecho a la educación universitaria y, en un futuro, contar con representantes políticos de origen mexicano. "Creo que la comunidad mexicana es transformativa, estamos aprendiendo de los movimientos de los ańos 50". Las ac- 
ciones político-pedagógicas de Cabrera son vistas a largo plazo, por eso la importancia de crear espacios para las futuras generaciones y, en especial, la atención a la niñez y a la juventud. Según sus propias palabras, la comunidad mexicana será la más grande entre las minorías, 1.6 millones en la Ciudad de Nueva York. El énfasis puesto a la construcción de espacios y la atención a los niños y jóvenes es visto como un horizonte para la representación política, estos niños que asisten a MASA van a llegar a votar como jóvenes. "Hay que empezar con la nińez y crear una comunidad fuerte, como le hacen otras comunidades y votar en bloques ...podemos exigir ... hay un bloque de respaldo... queremos un representante".

\section{CONSIDERACIONES FINALES Y PREGUNTAS PARA ABRIR EL DIÁLOGO}

A partir de las preguntas iniciales respecto a la configuración discursiva de nuestro protagonista como sujeto de derecho, es de llamar la atención el reconocimiento a su persona a partir del contacto y apoyo que recibió de su amiga sudcoreana, así como los micro-relatos al momento de escapar del sótano que lo tenía encadenado a una vida subterránea y oscura y el recibir apoyo de otra migrante. De ahí el sentido que adquiere salir de la sombra. Esto nos lleva a las reflexiones de Honneth (2010) sobre el desprecio y las injusticias en contextos migratorios.

Además, el interés genuino de continuar con sus estudios en la universidad, al momento de ser inscrito, independientemente de su condición migratoria, reafirma su naturaleza de sujeto de derecho, incluso a la educación universitaria, a recibir apoyo económico, becas y otro tipo de soporte para su permanencia en la universidad. Esto se conjunta a la irrupción del 9/11, que condensa su identidad de migrante con derechos. Como él mismo lo señala, "descubrí que un indocumentado tiene derechos".

El trayecto de vida y escolar de Angelo atraviesa el activismo político, el liderazgo en movimientos por la defensa del derecho a la educación que va desde la huelga de hambre para la defensa de los estudiantes por el alza de la inscripción, la gestación de MASA, 
la defensa de la lucha de los dreamers, los DACA, los retornados del DACA y ahora los niños y jóvenes transnacionales son fuente de su poderío, liderazgo y de su constitución de sujeto en el sentido de Laclau, cuando señala que el sujeto se constituye en el momento de la decisión.

La representación política de la comunidad mexicana es vista como un horizonte de posibilidad, articulada a la lucha por el derecho a la educación. De ir construyendo identidad, un bloque común para la exigencia de los derechos de las minorías en los Estados Unidos, de la representación, de alguna manera, del reconocimiento como ciudadanos de esa nación. Entre las significaciones que se construyen del derecho a la educación, sobresale el horizonte político, de lucha y el reconocimiento de los derechos de los migrantes.

Entre las reflexiones finales, cabe destacar el posicionamiento ético y político de la mirada cualitativa y el uso de las entrevistas a profundidad y los diálogos informales a lo largo de cuatro meses. Como se señaló en el apartado metodológico, ¿qué nos permite ver este caso para la comprensión del derecho a la educación en contextos migratorios? En principio, las condiciones de explotación y discriminación en la que viven nuestros migrantes mexicanos en el mundo laboral social y educativo, el sentirse vulnerables por no contar con la documentación oficial y, al mismo tiempo, empoderarse como sujetos de derecho por el acceso a la educación superior. Tal como lo señaló Honneth (2007), el reconocimiento de las personas y las colectividades y sus derechos posibilitan a los sujetos hacer frente y resistirse a las adversidades sociales y vivir desde otro lugar la migración.

\section{REFERENCIAS BIBLIOGRÁFICAS}

Aupetit, S. (2017). Vincular la internacionalización con las prioridades de desarrollo de las instituciones de Educación Superior: una urgencia inaplazable. Educação, 40(3), 324-332. https://doi.org/10.15448/19812582.2017.3.28975

Barros, M. (2017). Los efectos del DACA en la carrera profesional y las emociones de jóvenes migrantes. Estudios Fronterizos, 18(37), 131- 
148. https://doi.org/10.21670/ref.2017.37.a07

De Sousa, B. (2009). Una Epistemología del Sur. La reinvención del conocimiento y la emancipación social. Buenos Aires: Siglo XXI Editores, CLACSO.

Diaz-Strong, D., y Meiners, E. (2007). Residents, Alien Policies, and Resistances: Experiences of Undocumented Latina/o Students in Chicago's Colleges and Universities. UCLA Journal of Education and Information Studes, 3(2).

Elliot, J. (1991). Action Research for Educational Change. Bristol, Pennsylvania: Open University Press.

Enríquez, M., y Valdéz, G. (2018). La lucha por la inclusión a través de la Dream Act y el DACA: desafíos de integración educativa y social de familias de estatus migratorio mixto en Phoenix, Arizona. En Redes sociales y construcción de espacio público de migrantes transnacionales (pp. 97-119). Xalapa, Veracruz, México: Red Iberoamericana de Academias de Investigación, A.C.

Escobedo Avitia, M. (2016). Migración y Educación Superior. Caso jóvenes DREAMERS en Estados Unidos inscritos a la ley DACA (Maestría en Ciencias Sociales). México: Universidad de Sonora.

Gergen, M. M., y Gergen, K. J. (2012). Playing with Purpose: Adventures in Performative Social Science (Writing Lives). Reino Unido: Routledge. Gonzales, R. G., Terriquez, V., y Ruszczyk, S. P. (2014). Becoming DACAmented: Assessing the Short-Term Benefits of Deferred Action for Childhood Arrivals (DACA). American Behavioral Scientist, 58(14), 1852-1872. https://doi.org/10.1177/0002764214550288

Gonzales, R. G., \& Terriquez, V. (2013). How DACA is impacting the lives of those who are now DACAmentd: Preliminary Findings from the National UnDACAmented Research Project. Inmigration Policy Center, University of Southern California.

Hernández-Hernández, O. M. (2015). Niñas migrantes: relatos de menores mexicanas repatriadas de Estados Unidos. Methaodos. Revista de ciencias sociales, 3(1), 122-133. https://doi.org/10.17502/m.rcs. v3i1.76

Honneth, A. (2007). Reificación. Un estudio en la teoría del reconocimiento. Buenos Aires: Kats editores. 
Honneth, A. (2009). Critica al agravio moral. Patologias de la sociedad contemporánea. Buenos Aires: Fondo de Cultura Económica y Universidad Autónoma Metropolitana.

Honneth, A. (2010). Reconocimiento y menosprecio. Sobre la fundamentación normativa de una teoría social. Buenos Aires: Kats editores.

Kant, I. (2013). La Paz perpetua. Madrid: Tecnos.

Lee, S. (2015). Book Reviews. Growing up outside the law. Inmigration outside the law. By Hiroshi Motomura. Harvard Law Review, 128(5), 1405-1451.

Marín, A. (2018). El Programa DACA y sus implicancias geopolíticas y geoeconómicas para México. Instituto de Investigaciones Estratégicas de la Armada de México.

Martínez, J. (2000). Migración internacional de jóvenes latinoamericanos y caribeños: protagonismo y vulnerbilidad. CEPAL (Serie migraciones, No 3).

Nussbaum, M et al. (1994) Cosmopolitas o Patriotas. Buenos Aires. Fondo de Cultura Económica

Oliveira, G. (2017). Between Mexico and New York City: Mexican Maternal Migration's Influences on Separated Siblings' Social and Educational Lives: Between Mexico and New York City. Anthropology \& Education Quarterly, 48(2), 159-175. https://doi.org/10.1111/aeq.12191

Rumbaut, R. (2006). Edades, etapas de la vida y cohortes generacionales: un análisis de las dos primeras generaciones de inmigrantes en Estados Unidos. En A. Portes y J. DeWind (coords.), Repensando las migraciones. Nuevas perspectivas teóricas y empiricas (pp. 361-410). Zacatecas: Universidad Autónoma de Zacatecas y Miguel Ángel Porrúa.

Santillanes, N. I. (2017). Padecer la depresión como mujer inmigrante mexicana en la ciudad de Nueva York. Revista de Salud Pública, 19(6), 855-860. https://doi.org/10.15446/rsap.v19n6.70366

Smith, Robert. (2006). México en Nueva York. Vidas trasnsnacionales de los migrantes mexicanos entre Puebla y Nueva York. Zacatecas: Universidad Autónoma de Zacatecas y Miguel Ángel Porrúa.

Stake, R. E. 2005 Investigación con estudio de casos. Madrid, Morata.

Uribe, A. (2018). La figura de los padres en la experiencia migratoria de dreamers. Estudios sobre las Culturas Contemporáneas, 24(48), 103120. 
Valle, E. D. V., y Zepeda, R. A. (2017). Inmigración y educación en México. Los nuevos desafíos en la era Trump. Red. Revista de evaluación para docentes y directivos, 3(7), 36-50. 